\title{
Shifting Treatment Strategies to Prevent Early Relapse of Locally Advanced Rectal Cancer After Preoperative Chemoradiotherapy
}

\author{
Eun Jung Park \\ Division of Colon and Rectal Surgery, Department of Surgery, Gangnam Severance Hospital, Yonsei University College of Medicine, Seoul, \\ Korea
}

See Articles on Page 382-389

The advances in surgical methods and preoperative chemoradiotherapy (PCRT) over the past decades have paved the way to marked improvements in rectal cancer treatment. Surgical innovations on total mesorectal excision (TME) have allowed for anatomically sharp rectal dissection resulting in increased survival among patients with rectal cancer $[1,2]$. PCRT reduced local recurrence and improved overall survival, especially in locally advanced mid and low rectal cancer [2-4]. By shrinking tumor volumes and suppressing micrometastasis, favorable clinical outcomes, such as tumor down-staging and pathologic complete response, were achieved $[5,6]$. However, although multimodal treatments for locally advanced rectal cancers have decreased local recurrence by approximately $5 \%$ to $10 \%$, the risk for distant metastasis after PCRT and TME still exists [3].

The most common sites of recurrence among patients with locally advanced rectal cancer treated by PCRT with TME are as follows (in order of decreasing incidence): lung, liver, and locoregional lesions $[7,8]$. The predominant recurrence in the lungs is likely due to the lymphatic pathway for systemic circulation via iliac vessels in the mid and low rectal cancer [9]. The analysis of Ikoma et al. [8] in the University of Texas MD Anderson Cancer Center has revealed that the median time to recurrence after PCRT and surgical resection was shorter (at $\mathrm{P}=0.001)$ in the liver

Correspondence to: Eun Jung Park, M.D.

Division of Colon and Rectal Surgery, Department of Surgery, Gangnam Severance Hospital, Yonsei University College of Medicine, 20 Eonju-ro 63-gil, Gangnam-gu, Seoul 06229, Korea

Tel: +82-2-2019-3897, Fax: +82-2-3462-5994

E-mail:camp79@yuhs.ac

ORCID: https://orcid.org/0000-0002-4559-2690

(C) 2020 The Korean Society of Coloproctology

This is an open-access article distributed under the terms of the Creative Commons Attribution NonCommercial License (https://creativecommons.org/licenses/by-nc/4.0) which permits unrestricted noncommercial use, distribution, and reproduction in any medium, provided the original work is properly cited.
(11.2 months) than that in the lung (18.2 months) and locoregional lesions (24.7 months). They concluded that salvage surgery can prolong survival in patients with lung or liver recurrence; however, it may not benefit patients with locoregional recurrence.

Oh et al. [10] analyzed recurrence patterns of 2,215 patients with locally advanced mid and low rectal cancer treated with radical resection. The recurrence patterns of rectal cancer were consistent with those in previous reports. Early relapse within the first year after TME has occurred more often in patients treated by PCRT (vs. no PCRT) with the lung as a predominant site of recurrence. No significant difference was observed for local recurrence. Furthermore, pathologic nodal metastases were significantly associated with early recurrence. Late recurrence over three years in patients treated using PCRT was not significantly different from those without PCRT. Similarly, Kim et al. [11] have also reported that the incidence of early recurrence of distant metastasis was higher in patients who received TME and neoadjuvant chemoradiation than in those without PCRT. Tumor regression grade and yp node positivity were regarded as predictive factors for early recurrence. Because early relapse within one year is related to poor survival and systemic treatment failure, shifting to neoadjuvant treatment has been required [12].

Current treatment guidelines still recommend adjuvant chemotherapy in patients with rectal cancer receiving PCRT and TME regardless of the final postoperative pathologic stage. Although it is expected that adjuvant chemotherapy prevents micrometastasis and reduces risks for early relapse and distant metastasis of locally advanced rectal cancer, the exact role of adjuvant chemotherapy is still unclear $[3,13]$. The complete treatment efficacy of adjuvant chemotherapy on rectal cancer is hampered by poor compliance and increasing toxicities. In addition, the risk of distant metastasis from delaying surgical resection and variable treatment responses were considered as the drawback of PCRT. In these regards, total neoadjuvant therapy (TNT) has been suggested and approached by phase II or III clinical trials.

TNT is a treatment composed of chemotherapy (including induction or consolidation chemotherapy) and standard PCRT 
prior to TME [14]. TNT has several merits compared with current PCRT method. First, because surgery is done at the final step of the treatment process, compliance for chemotherapy, and period for reversal of protective stoma after surgery can be improved. Second, completion of all cycles of chemotherapy at full doses before surgery has potential advantages to decrease micrometastases and prevent disease progression. Third, TNT allows selection of patients who have good responses to TNT and utility of wait-and-see treatment with organ preservation. The results of ongoing trials for TNT are expected to answer the possibility of shifting treatment strategies to improve overall survival and prevent early relapse of locally advanced rectal cancer after PCRT and TME.

\section{CONFLICT OF INTEREST}

No potential conflicts of interest relevant to this article were reported.

\section{REFERENCES}

1. Heald RJ. A new approach to rectal cancer. Br J Hosp Med 1979; 22:277-81

2. Arbman G, Nilsson E, Hallböök O, Sjödahl R. Local recurrence following total mesorectal excision for rectal cancer. Br J Surg 1996;83:375-9.

3. Sauer R, Becker H, Hohenberger W, Rödel C, Wittekind C, Fietkau $\mathrm{R}$, et al. Preoperative versus postoperative chemoradiotherapy for rectal cancer. N Engl J Med 2004;351:1731-40.

4. Tural D, Ozturk M, Selcukbiricik F, Yildiz O, Elicin O, Turna H, et al. Preoperative chemoradiotherapy improves local recurrence free survival in locally advanced rectal cancer. J BUON 2013;18: 385-90.

5. Liefers GJ, Cleton-Jansen AM, van de Velde CJ, Hermans J, van Krieken JH, Cornelisse CJ, et al. Micrometastases and survival in stage II colorectal cancer. N Engl J Med 1998;339:223-8.

6. Swedish Rectal Cancer Trial; Cedermark B, Dahlberg M, Glimelius B, Påhlman L, Rutqvist LE, et al. Improved survival with preoperative radiotherapy in resectable rectal cancer. N Engl J Med 1997;336:980-7.

7. Ding P, Liska D, Tang P, Shia J, Saltz L, Goodman K, et al. Pulmonary recurrence predominates after combined modality therapy for rectal cancer: an original retrospective study. Ann Surg 2012; 256:111-6.

8. Ikoma N, You YN, Bednarski BK, Rodriguez-Bigas MA, Eng C, Das $\mathrm{P}$, et al. Impact of recurrence and salvage surgery on survival after multidisciplinary treatment of rectal cancer. J Clin Oncol 2017;35:2631-8.

9. Pihl E, Hughes ES, McDermott FT, Johnson WR, Katrivessis H. Lung recurrence after curative surgery for colorectal cancer. Dis Colon Rectum 1987;30:417-9.

10. Oh SG, Park IJ, Seo J, Kim YI, Lim SB, Kim CW, et al. Beware of early relapse in rectal cancer patients treated with preoperative chemoradiotherapy. Ann Coloproctol 2020;36:382-9.

11. Kim HG, Kim HS, Yang SY, Han YD, Cho MS, Hur H, et al. Early recurrence after neoadjuvant chemoradiation therapy for locally advanced rectal cancer: characteristics and risk factors. Asian J Surg 2020;44:298-302.

12. Huh JW, Kim CH, Lim SW, Kim HR, Kim YJ. Early recurrence in patients undergoing curative surgery for colorectal cancer: is it a predictor for poor overall survival? Int J Colorectal Dis 2013;28: 1143-9.

13. Kuebler JP, Wieand HS, O'Connell MJ, Smith RE, Colangelo LH, Yothers G, et al. Oxaliplatin combined with weekly bolus fluorouracil and leucovorin as surgical adjuvant chemotherapy for stage II and III colon cancer: results from NSABP C-07. J Clin Oncol 2007;25:2198-204.

14. Ludmir EB, Palta M, Willett CG, Czito BG. Total neoadjuvant therapy for rectal cancer: an emerging option. Cancer 2017;123: 1497-506. 